\title{
Guest Editorial The Contested One-Shot: Deconstructing Power Structures to Imagine New Futures
}

\section{Nicole Pagowsky}

For so long the one-shot has been the dominating force of how we engage in library instruction. There is a lot of meaning and debate saturated in this faux-innocuous activity, yet there is not always consensus as to how we define a one-shot. Is it doing a library "spiel" to demo a database, present the library website, or give a tour? Is it visiting a class once without an explicit connection to an assignment? Is it even embedding a learning object in a class without assessment feedback or other interaction? To have a central, salient definition of the one-shot for the purpose of this editorial, I view it as a standalone session, superficially (or not at all) connected to course content, that is tacked onto a class. Within a curriculum, the one-shot has no memory of where information literacy has been and no vision of where it is going. It is ephemeral within cycles of ineffectiveness. I am writing this guest editorial to talk this through and share my thoughts, and then invite you to share yours in a special issue of $C \mathcal{E} R L$ on the contested one-shot (see the Call for Proposals at the end). We do not need consensus but sharing different perspectives and exploring what "effective" teaching means is important to support our instruction programs. This guest editorial will discuss one-shots in the context of effective teaching practices; assessment; and power structures related to care-work and Equity, Diversity, and Inclusion (EDI). The hope is to expand our pedagogical imagination through questioning what appear to be common-sense practices in order to create better systems and structures. ${ }^{1}$

\section{Effective Teaching}

What do we actually mean when we say "effective?" This is difficult to identify and measure. Learning is messy and doing more one-shots does not equate with more effective teaching or guarantee student learning. I started to think about what was problematic with the one-shot in my first library job at a community college where I would teach a large amount of these singular sessions each semester. The issue is less about them being "one" and more about them often being tacked on to the curriculum, regardless of how many there were. This idea has persisted in my mind and is expressed well in a 2006 article I assign to iSchool students in my LIS course. Dane Ward explains that, "Students do not achieve information literacy by attending more library sessions. Rather, students learn relevant information skills when they are systematically

Nicole Pagowsky is Associate Librarian with a focus on curriculum and pedagogy at the University of Arizona Libraries. She is also adjunct faculty with the University of Arizona iSchool and teaches LIS 581: Information Literacy Pedagogy, nfp@arizona.edu. (02021 Nicole Pagowsky, Attribution-NonCommercial (https://creativecommons.org/licenses/by-nc/4.0/) CC BY-NC. 
integrated and sequenced throughout the curriculum." ${ }^{2}$ A common argument is that one-shots are better than nothing. Maybe. But just because it could be worse does not mean we should not hope for better. And one-shots actually could even be worse than nothing. Barbara Fister forewarns that focusing on superficial skills such as finding and evaluating sources are not sufficient and could cause harm. ${ }^{3}$ These superficial skills are the limits of what we can do in one-shot models. One-shots are transactional; content is requested and then deposited into students' minds with a focus on measurable skills. Christine Moeller relates these transactions to our field's service model where one-shots, rather than being collaborative pedagogy, are a service that librarians provide on behalf of faculty and students. ${ }^{4}$ Curricula unfold over time, which are at odds with the singular and repetitive one-shot. One-shots attempt to shoehorn the messiness and not-yetness ${ }^{5}$ of learning into a 50 minute session-or sometimes whittled down to 30 minutes or shorter as faculty feel they have less and less time to share. Looking at one-shots through the lens of time pushes back the curtain more. A connection is revealed between one-shots not being incorporated into the curriculum from lack of time (and space) to go beyond surface-level learning. Karen Nicholson in discussing the issue of temporality and the one-shot says,

I contend that if librarians have struggled to move beyond the one-shot model, it is in no small part because by virtue of its brief, episodic nature-one that can result only in a superficial skills-oriented approach - the one-shot is in perfect sync with the accelerated, fragmented "corporate time" chronos of contemporary higher education. ${ }^{6}$

The one-shot-even if there is more than one-makes it difficult to reach deeper learning, critical thinking, and inclusive pedagogy. The idea that we could expect to have an impact and demonstrate that it was as a direct result of library instruction is incredibly difficult to prove. Michael Carlozzi wrote about how one-shots often do not teach students the type or depth of concepts required to do well on their research assignments, particularly because students struggle with transfer of learning. When we must teach episodically and superficially, transfer of learning is often a goal out of reach. He explains, "Indeed, the well-documented shortcomings of library one-shot sessions persist in no small part from the teaching faculty's preference that students find and independently negotiate research." 7 So, having multiple sessions or being superficially embedded in the course does not resolve the problems inherent in the one-shot model. We are fitting a square peg into a round hole by trying to force one-shots to work as we hope they could. Kirsten Hostetler and Tian Luo describe one-shots' shortcomings and provide research on how to improve them through examination of student engagement and cognitive load. This seems beneficial for instruction programs that have few options other than to continue employing the one-shot. The authors explain, "Information literacy competency showed extremely limited gains following instruction to both groups, shedding light on the need for real, practical strategies that can improve the efficacy of these sessions." ${ }^{8}$ Although these findings are valuable, there is a problem when we as a field have evidence that this instructional approach is not effective for student learning but must find workarounds to fit that square peg, rather than change our practices and expectations. We are stuck within structures that present barriers to change. 


\section{Assessment, Measurement, and Outputs}

Barriers to change are also present in how we measure the success of these structures. Discrepancy on what effective means, and then how to measure this nebulous understanding, puts us at odds with assessment of learning and evaluation of our outputs. The pressure of doing quantitatively more to prove value is problematic not only to student learning by reinforcing demand for one-shots (either by librarians trying to meet a number, or by feeling required to say yes to faculty requests), but also to our own sustainability. Patrick Bigger and Morgan Robertson are a beacon of clarity in questioning what we value and therefore what to measure:

But if value is the debate about how we estimate things relative to a moral horizon, there is no more important work. Arguing about whether one thing is taller or bluer or more expensive than another is important, but so is the decision that inches, electromagnetic frequency, or dollars will be the measure used, and so is a discussion of who these decisions marginalize and silence. The measurement of the thing is not as important as the settlement about what measurement is and what ruler will be used. ${ }^{9}$

Whether measuring student learning by quantity of one-shots, or librarian productivity by the number of faculty requests and time spent on sessions, this does not adequately demonstrate student learning, good teaching, nor collaborative relationships with faculty. Just like how the amount of time students spend in an LMS does not show causation of better grades; ${ }^{10}$ or for how students who already have high GPAs, using the library does not prove the library caused their greater success; again: doing more one-shots does not mean we have robust, pedagogically-sound instruction programs with productive faculty collaborations. We need to be cautious in our intent and also how we present results. M. Brooke Robertshaw and Andrew Asher provide a detailed investigation of how library analytics pointing to student success have often over-interpreted results and exaggerate the library's effect on learning. The heart of the issue is "[inappropriate and egregious descriptions of] small p-values with adjectives like 'massive' significance, which is an incorrect characterization since, as p-values indicate probability, they do not have size values attached to them. These types of incorrect descriptions contribute to confirmation bias, overinterpretation of results, and reporting correlation as implied causation." ${ }^{11}$ Learning is vast and unpredictable and can be difficult to measure. Honestly and openly reflecting on what we value and understanding those implications is essential to matching our measurement with our values. We also must differentiate our values from showing "value." Basing how we demonstrate our value on factors external to the heart of student learning is reactionary and does not work to our students' benefit, nor ours for sustainable work. Karen Nicholson, Nicole Pagowsky, and Maura Seale articulate, "Anxiety and fear of the future may prevail if academic libraries are beholden to campus efforts to use student data to demonstrate value, pushing librarians toward a pedagogy centered in the development of measurable skills."12

\section{Power Structures and Care Work}

When anxiety drives us to create proof that we are successful in our performance and pedagogy to prove our value, we diminish our ability to see obstacles clearly. The way we engage in teaching within one-shot models, and the associated expectations for measurement, both 
keep us in a holding pattern of reactionary yes-people unable to enact our own agency within campus power structures. If we keep centering our model of quantifiable success within our instruction programs, our libraries, and our campuses, as Nicholson states again regarding time in 2019, "Librarians trapped between devaluation of their time by faculty (last-minute requests for spiels) and demand for producing measurable outputs by administrators - makes it hard to refuse [one-shot] requests." ${ }^{13}$ What we are able to do pedagogically in the one-shot relies on transactions through individual faculty approval and our own institution's expectations for output and measurement. The fabric of transaction is practicality, which prioritizes efficiency and is framed as common sense. David Hudson makes clear that when guided by practicality, normative value structures persist in their power,

[T] he focus of analysis is not on our commitment to prioritizing user needs, but rather on the operations of practicality as a dominant value. Turning as it does on relational exaltations of the practical and devaluations of the theoretical, the imperative to be practical is indeed truly hegemonic. ${ }^{14}$

What is practical becomes omnipresent and thought of as harmless. It is difficult to question our structures and pushback on "how we've always done it" when it is made to appear as common sense. Faculty request a spiel and we give it to them, providing good service. One-shots seem like a no-brainer, giving more staying power to our hegemonic structures that solidify this model. Our own agency and freedom to say "no" are imperative for moving beyond the barriers one-shots impose. Gloria Leckie and Anne Fullerton in writing about power and information literacy back in 1999 say,

Furthermore, as an object that is surrounded by discourses, information literacy cannot be viewed as separate from the power relations on campus. Librarians have tended not to see how information literacy activities construct and generate power, nor how their own pedagogical discourses may actually hamper their efforts to work with faculty. ${ }^{15}$

Not much has changed in twenty years. We need to become more comfortable with saying "no" when working collaboratively with faculty to reduce demand and expectation for one-shots. However, this is not easy when faculty expectations for one-shots are commonplace and when our institutional expectations for practical, good service take precedence over the complexity and messiness of good pedagogy.

Instruction programs run heavily on service through emotional labor and care work - which tend to be invisible. Focus on quantity through endless cycles of one-shots erases this labor further. Lisa Sloniowski notes the "glorification of concrete outputs in performance measurements over emotional labor as an example of the ways in which care work is devalorized in relation to other tasks." ${ }^{16}$ This approach to emphasize quantity reduces complex, multi-dimensional work into simplistic pieces to gather and check off a list. It brings us back to examining what we value and determining if these constructs and forms of measurement are actually leading us astray, and potentially causing harm. Maura Seale and Megan Browndorf put this in perspective of libraries valuing what can be seen, and from there measuring what is visible; where tasks are prioritized over work because they are easier to identify. These tasks are often valued more and 
are at odds with lower-valued feminized care work, such as service roles and instruction. ${ }^{17}$ To break up complex care-work into easily measurable tasks and to equate value with quantity gives the appearance of perceived success. Melissa Bowles-Terry and Carrie Donovan add, "In these ways, the perceived success is holding librarians back from making large-scale changes, thereby perpetuating a cycle of librarians as reactive problem-solvers and guest lecturers rather than curriculum developers and change agents." ${ }^{18}$ One-shot models essentially create a checkbox that gives us the appearance of success based on numerical accomplishments. What we are valuing clashes with a deeper characterization of "effective" teaching and our own wellbeing.

Where do we find the time and space to improve our pedagogy or program structures when we have so many one-shot requests each year that we feel pressure to take on repeatedly? While not mutually exclusive, good service does not automatically equate with good pedagogy. Yvonne Meulemans and Allison Carr discuss the difference between the two and the importance of being able to say no, "The 'customer is always right' attitude is not effective teaching or collaborative philosophy." ${ }^{19}$ When we constantly say yes to one-shots, we are helpers and assistants, and sometimes even, sadly, babysitters. We become beholden to cycles of ineffectiveness that create burnout. Oppressive systems inherently exhaust. They prevent us from implementing collaborative relationships of care across campus and hinder our ability to fully engage in thoughtful and "effective" pedagogy. In discussing anxiety, a pervasive sense of precariousness, and being overloaded, Sloniowski reminds us that, "In academia one must be always psychically and somatically prepared for work that has no beginning and no end." 20 This is burnout and disenfranchisement. Although not easy, when we are able to advocate for ourselves and have the power to say no, we can focus our work as campus change agents and curriculum developers. We are proactive rather than reactive, and we hold power for ourselves as partners.

\section{Power Structures and EDI}

We can recognize our work as feminized labor and have a greater understanding as to why it becomes invisible and the irrationality of its measurement. However, there are also implications for EDI from our systems, structures, and policies where we must also understand exponential effects on BIPOC librarians and those with intersectional identities. Like many practical structures within libraries, could the one-shot model be white supremacist? Gina Schlesselman-Tarango describes whiteness as refusing to acknowledge itself, "asserting itself as universal rather than racially marked, historically produced, and oppressive. In its facade of universality, it claims to be for (or about) everyone while at the same time being against none." ${ }^{21}$ The one-shot model poses as common sense, universal, practical, harmless, and so on; yet, when we question and investigate this model, it reveals that it does in fact cause harm.

In considering "neutral" and white supremacist structures such as libraries and academia, Kawanna Bright emphasizes the high levels of emotional labor via surface and deep acting for women BIPOC librarians, and how much invisible labor is especially present in these conditions. ${ }^{22}$ When revealing how much additional labor BIPOC librarians must endure within libraries' bureaucratic structures, and how much these structures further marginalize, Lalitha Nataraj et al. explain that,

Ultimately, the emotional and interpretive labour of working in such gendered, raced, and classed environments takes so much effort that it leaves no space for women, especially those who identify as BIPOC, to think about their own perspec- 
tive or how to voice perspectives that may deviate from what is considered and accepted as the norm; in this respect, they are left to engage in absurd practices in ways that are guided by and satisfy those in management. ${ }^{23}$

There are power disparities in place within libraries that make it unsafe for women BIPOC librarians to voice concerns or push back against the status quo. Hudson expands on this barrier, "It is difficult to explore the violence of status quo discourse where one's environment is governed by the exaltation of clarity, plain language, the everyday, the utilitarian transmission of content, the acceptance of normalcy as a basis for proceeding." ${ }^{24}$ What then is the effect of care-heavy work, such as instruction (and specifically one-shots), in these situations of intense emotional labor where it is already difficult to say no or deviate from demands and expectations? Tarida Anantachai and Camille Chesley describe that, "The intersections between the burden of care and cultural taxation faced by women of color in higher education are already apparent. For women of color librarians, the burdens they face as a result of their intersectional identities are further exacerbated by their professional characterization as care workers." ${ }^{25}$ When we understand how difficult it is to say no for most based on these structures, we should see how much more difficult it might be for women BIPOC librarians to feel safe in pushing back on these models. The cultural taxation of heavy service commitments (without the security to say no) impede BIPOC academics in earning tenure, causing a "leaky pipeline" from terminal degree to full professor. ${ }^{26}$ It should be clear that being buried in cycles of one-shots without options to say no can contribute to this damage and to lack of retention within the library profession. If we claim we value inclusive and equitable libraries, we need to question our practices and make it safe and supportive for everyone to speak up--especially those marginalized by these systems and practices.

To do this, we need to work collectively at all levels. In our instruction programs, we can train individual instruction librarians endlessly on the most effective strategies for persuasion or feeling more confident in saying no, but without departmental and administrative advocacy, it becomes a stressful - and a potentially futile-endeavor. Regarding a lower-level of leadership from instruction coordinators, Veronica Arellano Douglas and Joanna Gadsby make the limitations of this role clear by describing how little authority a coordinator has and how they are typically not empowered to make large-scale changes without the intervention of a department head or administrator. ${ }^{27}$ So even if a coordinator hopes to advocate for instruction librarians' agency, how the department or the library as a whole determines success can negate this. Creating opportunities for inclusive pedagogy in the curriculum should also ensure we examine our own practices to work collectively and inclusively within libraries. To just develop critical lesson plans without examining how our neutral-posing structures and policies harm library workers is hypocritical, and as Jennifer Ferretti points out, can be viewed as performative. ${ }^{28}$ Alfie Kohn talks about how damaging a deficit mindset about students' abilities can be, and that when we believe students to be incapable we continue to do the same thing over and over (because they are the problem, not our teaching), and this lets us off the hook. ${ }^{29}$ In thinking about policies that harm, I would argue the same idea can be turned back on ourselves. When libraries remain within oppressive structures where feminized labor is invisible and devalued, there is a deficit mindset that allows the use of the same models and hegemonic structures over and over without question or improvement. What is important for the success of our programs and ourselves is for administration, and ideally campus, to 
value care-work and to support a culture in the library for critical and proactive approaches to our instruction programs and institutional structures.

\section{Creating A New Future}

One-shots are transactional and keep us in cycles of ineffectiveness. They cause burnout. As the antithesis of collaborative work and collective action, they perpetuate silos. It is everyone for themselves measured in quantity. There have to be other options to develop more collaborative relationships with support for different approaches to teaching and measurement. Ultimately, if libraries purport to be inclusive and equitable institutions, we need support from leadership to investigate neutral-posing norms that paint over dominant practices, which cause harm. As stated, we can do all the planning and training we want on how to be more persuasive with faculty, and it is not all for naught; but if we are left on our own, particularly for those having intersectional identities, the struggle for a more manageable and successful instruction program starts from inequity. This is similar to narratives about self-care where the onus is put on the individual worker rather than looking at structural concerns in organizations. If the problem is presented as just being that the workers as individuals are "stressed," the institution does not have to do anything. Offering free meditation or a pizza party are null and void solutions that allow the status quo to continue, without working to solve structural issues. As Nataraj et al. state, we need to disrupt current systems to be able to imagine more liberatory futures. ${ }^{30}$ The systems that have created and sustained the one-shot are oppressive. When trapped in this cycle, our pedagogical imagination is limited. We need a new way. Saidiya Hartman states that "So much of the work of oppression is about policing the imagination." 31 Policing the imagination can be present in a variety of forms. When "common sense is a deceptive ally in challenges to domination," speaking theoretically and dreaming new futures are eschewed for practicality and accepting how we've always done it. ${ }^{32}$ We need to make the space to engage collaboratively so we can imagine bigger. Fabulation is one approach, to reimagine in-place systems and structures for change, and to turn these imaginings into reality. Through resisting "everything that crushes and imprisons," 33 "engaging in fabulation could be a way to reinvent our discourse in higher education and academic libraries. It works to dissolve binaries, to disrupt judgment, and to question of what we prescribe value." 34 Sofia Leung and Jorge López-McKnight point us to accountability and pushing back on these common, long-standing oppressive structures:

Real, impactful change cannot happen only in library instructional spaces if we truly believe in critical library instruction and social justice. The way forward means we cannot forget the racist, misogynistic, capitalist, colonialist history and legacy of libraries and how that impacts our instruction, day-to-day work, relationships with students, faculty, staff, and each other. We have to hold one another accountable to what we say we want to do, rather than allow institutions and organizations steeped in that legacy - that are reliant on exploitative relations and dehumanization to function - to continue functioning that way. ${ }^{35}$

It is a collaborative effort that needs to be sustained, and it will take larger conversations, more transparency, and different expectations to change these structures. 


\section{Acknowledgments}

Thank you to Lalitha Nataraj, Karen Nicholson, Annie Pho, and Maura Seale for reviewing drafts by request and providing thoughtful and insightful feedback.

\section{Call for Proposals}

$C \mathcal{E} R L$ is seeking proposals for a special issue on library instruction and the one-shot. This guest editorial provided context surrounding these conversations, and this special issue will offer a platform to continue the discussion. Agreement, disagreement, and anything in between are welcomed and encouraged. Goals of this issue include to advance understanding of the pedagogy of one-shots, our relationships with campus, instruction program structures, impact on EDI, and libraries' own internal functioning. The hope for this issue is to get a variety of perspectives.

Proposal submissions may include but are not limited to:

- How one-shots help or hinder our campus-wide instruction efforts

- How pedagogy is affected by one-shot models, with focus on learning models, educational theory, or critical pedagogy

- Burnout, turnover, and low morale of instruction librarians engaged in one-shotfocused teaching

- Burnout, turnover, and low morale related to tenure and retention for BIPOC librarians and others from marginalized groups engaged in one-shot-focused teaching

- One-shots as white supremacy or faux-neutrality

- The effects of expectations for positivist teaching approaches in one-shots that erase or leave out other ways of knowing (such as Indigenous research practices)

- How one-shots fit into relational and care work-based instruction programs

- One-shots' impact on instruction as feminized labor

- Other labor-related or critical models that speak to the impact of one-shots

- Assessment, measurement, and analytics in terms of the one-shot

- Dreaming and imagination: where do we go, what is ideal? (Submissions in this category can be less formal, and creative or exploratory.)

Approaches to exploring these topics can take multiple approaches, such as theoretical, practical, qualitative, quantitative, philosophical, and other ways of knowing. Manuscripts $(\sim 3,000-6,000$ words) will go through a peer-review process. CERL uses The Chicago Manual of Style, 16th Ed. See more on author guidelines here: https://crl.acrl.org/index.php/crl/about/ submissions.

Proposals should include:

- Author name(s), contact information, and affiliation

- Tentative title or focus

- A proposal/abstract of no more than 500 words

Please submit proposals through this form (https://forms.gle/Xv5beLAJWrHxFgkn8) by July 1, 2021. Contact the guest editor, Nicole Pagowsky, with any questions at nfp@arizona. edu. Also please contact Nicole if you have expertise in any of these areas and would like to be a peer-reviewer for this special issue, regardless of if you submit a proposal or not. 


\section{Notes}

1. Although this piece is intended to be more theoretical, I do want to point out some examples of the work others have done offering more concrete suggestions for better systems and structures aligning with my viewpoints: not being in the classroom as much, or at all, and instead working with faculty for them to teach IL in their courses (Risë Smith, 1997; Sandra Cowan \& Nicole Eva, 2016); focusing on train-the-trainer or teach-theteacher models (lit review on this topic by Jane Hammons, 2020); and incorporating CILAC, or critical information literacy across the curriculum (Margaret Torrell, 2020). Though I agree with curricular integration of CIL, I do not think we should be doing more instruction sessions to implement this, but rather be in the classroom less through a collaborative relationship with faculty for them to incorporate CIL seamlessly within their own courses. I also previously wrote some aspirational wording (that has not been formalized) on reducing oneshots: https://libguides.library.arizona.edu/c.php?g=463822\&p=3170646.

2. Dane Ward, "Revisioning Information Literacy for Lifelong Meaning," The Journal of Academic Librarianship 32, no. 4 (July 2006): 400.

3. Barbara Fister, "Lizard People in the Library," Blog, Project Information Literacy Provocation Series (blog), February 3, 2021, https://projectinfolit.org/pubs/provocation-series/essays/lizard-people-in-the-library.html.

4. Christine M. Moeller, "Insert Instruction Here," in Deconstructing Service in Libraries: Intersections of Identities and Expectations, ed. Veronica Arellano Douglas and Joanna Gadsby (Sacramento, CA: Library Juice Press, 2020), 238-39.

5. Amy Collier, "Not-Yetness," Blog, The Red Pincushion (blog), April 15, 2015, http://redpincushion.us/blog/ teaching-and-learning/not-yetness/.

6. Karen P. Nicholson, "'Taking Back' Information Literacy: Time and the One-Shot in the Neoliberal University," in Critical Library Pedagogy Handbooks, ed. Nicole Pagowsky and Kelly McElroy, vol. 1, 2 vols. (Chicago: ACRL, 2016): 26-27.

7. Michael Carlozzi, “They Found It--Now Do They Bother? An Analysis of First-Year Synthesis,” College $\mathcal{E}$ Research Libraries 79, no. 5 (2018): 660.

8. Kirsten Hostetler and Tian Luo, "Managing Cognitive Load in Information Literacy Instruction," Educational Technology Research and Development, (2021): 18-19.

9. Patrick Bigger and Morgan Robertson, "Value Is Simple. Valuation Is Complex," Capitalism Nature Socialism 28, no. 1 (January 2, 2017): 71.

10. A student could have left their browser open while logged into the LMS for hours without doing any work; a student could already be familiar with the content and so does not need to spend as much time with materials; or a course could be designed poorly causing students to spend a lot of time navigating it while not doing well (or just giving up).

11. M. Brooke Robertshaw and Andrew Asher, “Unethical Numbers? A Meta-Analysis of Library Learning Analytics Studies," Library Trends 68, no. 1 (2019): 91.

12. Karen P. Nicholson, Nicole Pagowsky, and Maura Seale, "Just-in-Time or Just-in-Case? Time, Learning Analytics, and the Academic Library," Library Trends 68, no. 1 (2019): 66.

13. Karen P. Nicholson, "'Being in Time': New Public Management, Academic Librarians, and the Temporal Labor of Pink-Collar Public Service Work," Library Trends 68, no. 2 (2019): 143.

14. David James Hudson, "The Whiteness of Practicality," in Topographies of Whiteness: Mapping Whiteness in Library and Information Studies, ed. Gina Schlesselman-Tarango (Sacramento, CA: Library Juice Press, 2017): 205.

15. Gloria Leckie and Anne Fullerton, "The Roles of Academic Librarians in Fostering a Pedagogy for Information Literacy" (Association of College \& Research Libraries, Detroit, MI: ACRL, 1999): 9. https://alair.ala.org/ bitstream/handle/11213/15969/leckie99.pdf?sequence=1\&isAllowed=y.

16. Lisa Sloniowski, "Affective Labor, Resistance, and the Academic Librarian," Library Trends 64, no. 4 (2016): 658.

17. Maura Seale and Megan Browndorf, "Service, Gender, and Liaison Librarianship," in Deconstructing Service in Libraries: Intersections of Identities and Expectations, ed. Veronica Arellano Douglas and Joanna Gadsby (Sacramento, CA: Library Juice Press, 2020): 20.

18. Melissa Bowles-Terry and Carrie Donovan, "Serving Notice on the One-Shot: Changing Roles for Instruction Librarians," International Information \& Library Review 48, no. 2 (April 2, 2016): 138.

19. Yvonne Nalani Meulemans and Allison Carr, "Not at Your Service: Building Genuine Faculty-librarian Partnerships," ed. Jennifer Rosenfeld, Reference Services Review 41, no. 1 (February 15, 2013): 83.

20. Sloniowski, "Affective Labor, Resistance, and the Academic Librarian": 658

21. Gina Schlesselman-Tarango, "How Cute! Race, Gender, and Neutrality in Libraries," Partnership: The 
Canadian Journal of Library and Information Practice and Research 12, no. 1 (August 22, 2017): 7.

22. Kawanna Bright, "A Woman of Color's Work Is Never Done: Intersectionality, Emotional, and Invisible Labor in Reference and Information Work," in Pushing the Margins: Women of Color and Intersectionality in LIS, ed. Rose Chou and Annie Pho (Sacramento, CA: Library Juice Press, 2018): 163-95.

23. Lalitha Nataraj et al., "'Nice White Meetings': Unpacking Absurd Library Bureaucracy through a Critical Race Theory Lens," Canadian Journal of Academic Librarianship 6 (December 18, 2020): 10.

24. Hudson, "The Whiteness of Practicality": 212.

25. Tarida Anantachai and Camille Chesley, "The Burden of Care: Cultural Taxation of Women of Color Librarians on the Tenure-Track," in Pushing the Margins: Women of Color and Intersectionality in LIS, ed. Rose Chou and Annie Pho (Sacramento, CA: Library Juice Press, 2018): 303.

26. Social Sciences Feminist Network Research Interest Group, "The Burden of Invisible Work in Academia," Humboldt Journal of Social Relations 39 (2017): 228-45.

27. Veronica Arellano Douglas and Joanna Gadsby, "Gendered Labor and Library Instruction Coordinators" (Association of College \& Research Libraries, Baltimore, MD: ACRL, 2017): 271.

28. Jennifer Ferretti, "Building a Critical Culture: How Critical Librarianship Falls Short in the Workplace," Communications in Information Literacy 14, no. 1 (June 2020): 134-152.

29. Alfie Kohn, "Foreword," in Ungrading: Why Rating Students Undermines Learning (and What to Do Instead), ed. Susan Blum (Morgantown: WV: West Virginia University Press, 2020): xv.

30. Nataraj et al., “'Nice White Meetings'": 12.

31. Sasha Ann Panaram, "'So Much of the Work of Oppression Is Policing the Imagination.' -- Saidiya Hartman \#UnderTheBlacklight," @SashaPanaram (Twitter), August 5, 2020, https://twitter.com/SashaPanaram/ status/1291173243169251328.

32. Hudson, "The Whiteness of Practicality": 212.

33. Mike Murphy and Elizabeth J. Done, "Towards a Deleuzo-Feminist Ethics of Empowerment and Freedom from Logics of Judgement," Gender and Education 27, no. 5 (July 29, 2015): 550.

34. Nicole Pagowsky, "A Pedagogy of Inquiry," Communications in Information Literacy 9, no. 2 (2015): 141.

35. Sofia Leung and Jorge López-McKnight, "Dreaming Revolutionary Futures: Critical Race's Centrality to Ending White Supremacy," Communications in Information Literacy 14, no. 1 (June 2020): 22. 